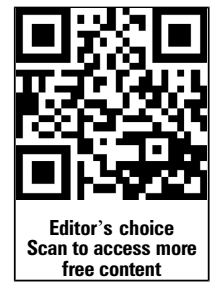
published online. To view please visit the journal (http:// dx.doi.org/10.1136/oemed2013-101948)

MRC Lifecourse Epidemiology Unit, University of

Southampton, Southampton, UK

\section{Correspondence to}

Professor Palmer, MRC

Lifecourse Epidemiology Unit, University of Southampton

S016 6YD, UK:

ktp@mrc.soton.ac.uk

Received 25 October 2013 Revised 29 January 2014 Accepted 11 February 2014 Published Online First 13 March 2014
CrossMark

To cite: Palmer $\mathrm{KT}$, D'Angelo S, Harris EC, et al. Occup Environ Med 2014;71:308-312.

\title{
The role of mental health problems and common psychotropic drug treatments in accidental injury at work: a case-control study
}

\author{
Keith T Palmer, Stefania D'Angelo, E Clare Harris, Cathy Linaker, David Coggon
}

\begin{abstract}
Objectives Mental illness and psychotropic drugs have been linked with workplace injury, but few studies have measured exposures and outcomes independently or established their relative timings. To address this shortcoming, we conducted a case-control study nested within a database prospectively recording injury consultations, diagnoses and drug prescriptions. Methods The Clinical Practice Research Datalink logs primary care data for $6 \%$ of the British population,

\section{What is already known on this subject}

Mental illness and psychotropic drugs have been linked with occupational injury in earlier studies, but inability to measure exposures and outcomes independently, or to establish their relative timings, may have led to risks being overestimated.
\end{abstract} coding all consultations (by the Read system) and drug prescriptions. We identified 1348 patients aged 16-64 years from this database who had consulted a family doctor or hospital over a 20-year period for workplace injury (cases, 479 diagnostic codes) and 6652 age, sex and practice-matched controls with no such consultation. Groups were compared in terms of consultations for mental health problems (1328 codes) and prescription of psychotropic drugs prior to the case's injury consultation using conditional logistic regression.

Results In total, 1846 (23\%) subjects had at least one psychiatric consultation before the index date and 1682 (21\%) had been prescribed a psychotropic drug. The OR for prior mental health consultation was $1.44(p<0.001)$ and that for psychotropic drug treatment was 1.57 $(p<0.001)$. Risks were significantly elevated for several subclasses of mental health diagnosis (eg, psychosis, neurosis) and for each of the drug classes analysed. Assuming causal relationships, about $9-10 \%$ of all workplace injuries leading to medical consultation were attributable to mental illness or psychotropic medication. Conclusions Mental health problems and psychotropic treatments may account for an important minority of workplace injuries.

\section{BACKGROUND}

Common mental health problems and prescribed psychotropic medicines have the potential to cause drowsiness and impair judgement, alertness and vigilance. In theory, therefore, such illnesses and treatments might increase risks of occupational injury. In an earlier review, ${ }^{1}$ we identified 15 reports that assessed injury risks at work in relation to mental illness ${ }^{2-16}$ and 9 in relation to medication. ${ }^{14}{ }^{17-24}$ More recently, there have been a few further studies. ${ }^{25}{ }^{26}$ Findings to date are compatible with a modest elevation of risk.

However, many previous investigations could have overestimated risks since typically both exposures and outcomes were ascertained by self-report after the event. Bias can arise in these circumstances

\section{What this study adds}

Using a database that overcame these problems, we focused on events that preceded medical injury consultation. Prior mental health diagnoses and psychotropic drug prescriptions were associated with significantly higher risks of injury consultation. About $9-10 \%$ of all workplace injuries leading to medical consultation appeared to be attributable to these factors.

from non-independence in measurement of exposures and outcomes (common instrument bias) and reverse causation. For example, workers who perceive and report more anxiety on a screening questionnaire may more readily recall minor injuries at work, while workplace injury may cause anxiety neurosis (or lead to its diagnosis), rather than being consequent upon it. We found only a few cohort and case-control studies in which these two concerns were overcome by independent assessment of exposure and outcome and by assurance regarding the timing of exposures (eg, tranquilliser use and low mood) relative to injuries. However, two higher quality studies adopted a preferable approach in which events and their timings were corroborated using hospital billing records and dispensary databases. ${ }^{14} 20$

In view of the limitations in the existing evidence base, we undertook a case-control analysis nested within a dynamic cohort of patients for whom consultations for workplace injury, other diagnoses and drug prescriptions had been recorded prospectively, with full information on the dates of events.

\section{METHODS}

Since 1987 the Clinical Practice Research Datalink (CPRD) (formerly the GPRD) has logged all 
consultation episodes associated with significant events, illnesses or medical activity (eg, diagnosis, referral, hospital admission, prescription) among patients from participating general practices across Great Britain. ${ }^{27}$ Records are maintained by the Medicines and Healthcare Products Regulatory Agency (MHRA) of the Department of Health and relate to some five million patients from 590 practices. Data are uploaded monthly and screened for completeness and validity. A nested case-control analysis was undertaken within the cohort of patients registered on this database at any time between 1 January 1987 and 31 December 2009.

CPRD consultation episodes are classified by Read diagnostic codes. In a scoping exercise, we identified 479 codes for occupational injury, ranging from the non-specific (eg, codes L5250W 'accident at work', T920 'accident on duty') through to events distinguishable as involving machinery or tools likely only to be used during work (eg, TG31400 'Accident caused by forging machine', TG37500 'Accident caused by transmission pulley'), plant or off-road vehicles at work (eg, T605.00 'Accident involving industrial self-propelled truck') or in work locations (eg, T736.00, 'Place of accident or poisoning, industrial yard'). Online supplementary appendix 1 provides a full list. The MHRA supplied us with an anonymised dataset containing the full primary care medical records of 9612 cohort members comprising (1) 1602 patients who had consulted their general practice or attended hospital with a qualifying injury code during 1987-2009 (cases) and (2) 8010 patients with no workplace injury (controls). A predefined algorithm was applied to match the controls individually to cases (five per case) by sex, nearest year of birth, general practice and being in the database at the time of the matched case's injury consultation.

All coding decisions and analyses were undertaken in relation to an index date-for a case, the date of their injury consultation and, for controls, the date of injury consultation of their matched case. Subjects who were $\geq 65$ years on the index date $(n=1476)$ were excluded as were a few controls matched to more than one case $(n=69)$, and a few cases and their matched controls where the underlying injury was found to be nonaccidental (eg, assault at work) $(n=67)$. Thus, analysis was based on 8000 subjects, comprising 1348 cases and 6652 controls, and exposures of interest (illnesses, treatments) were counted only if prior to the index date.

Diagnostic codes for psychiatric illness, based upon the Read system, were supplied by the first author of a report for the Home Office that had employed CPRD data to investigate mental health problems (with kind permission of Frisher et $\mathrm{al}^{28}$ ). The 1328 codes had originally been grouped into six diagnostic categories: (a) neurosis, (b) psychoses, (c) paranoia, (d) schizophrenia, (e) personality disorders and (f) other disorders (which includes 'insomnia not otherwise specified', 'behaviour problems', 'hallucinations', 'hallucinations auditory', 'behaviour antisocial' and 'disorder behaviour'). For the purposes of this analysis, the 416 codes recorded in our study subjects (see online supplementary appendix 2) were aggregated similarly, although category (c) was later omitted, there being no subjects with the diagnosis before the index date. All subjects were coded as having (or not having) one or more of these mental health problems at any time before the index date and at least 12 months before the index date.

Prescriptions with psychotropic or hypnotic effects were ascertained using the British National Formulary codes for hypnotics (code *04010100*), anxiolytics (*04010200*), barbiturates $(* 04030100 *$ or $* 04030200 *$ or $* 04030300 *$ or $* 04030400 *)$ and antidepressants $\left(* 04010300^{*}\right)$. The full list included sedative antihistamines and all the commonly prescribed categories of antidepressant, as well as drugs with potential to cause sedation but sometimes used for other purposes (eg, control of incontinence). Online supplementary appendix 3 lists all the medicines and codes. Subjects were coded as being or not being prescribed one or more of these drugs at any time before the index date and during the 12 months before the index date.

Associations between injury consultation and prior mental illness or psychoactive treatment were assessed using conditional logistic regression, with findings expressed as ORs with associated 95\% CIs. Analysis adjusted for a history of problem drinking (identified through a search for codes relating to alcohol misuse, alcoholic medical complications and high weekly intake-details available upon request).

Where risks were significantly elevated, we calculated the attributable fraction in the exposed using the standard formula (RR-1)/RR, where RR is the relative risk, and the population attributable fraction by the formula $\mathrm{Pe}^{*}((\mathrm{RR}-1) / \mathrm{RR})$, where $\mathrm{Pe}$ represents the proportion of exposed injury cases. These ratios can be interpreted as the attributable fractions of injury consultations in exposed persons and the total population, respectively, assuming that measured associations were causal.

Finally, in a sensitivity analysis, we explored associations according to the type of occupational injury and the external cause, and assessed risks in relation to 'severe' injuries, defined as those involving any of fracture, traumatic amputation or hospital attendance.

\section{RESULTS}

The final sample had a mean age of 39.9 (SD 12.7) years and included 5915 men. Among the cases, details on the circumstances and nature of the injury were commonly missing, but, where recorded, injuries often involved power tools, machinery, burns or poisonings, and quite often resulted in sprains, soft tissue injuries or lacerations and open wounds (table 1). In all, 159 cases $(12 \%)$ had attended hospital, while 230 cases $(17 \%)$ had been issued with a medical certificate to cover absence from work.

Prior to the index date, at least one consultation for psychiatric illness had occurred in 1846 (23\%) of the 8000 subjects, and 1682 subjects $(21 \%)$ had been prescribed at least one psychotropic medicine. The most common reason for consultation was neurosis (1437 subjects), followed by psychosis (651

Table 1 Nature and circumstances of the injuries in cases

\begin{tabular}{|c|c|c|c|}
\hline Injury & $\begin{array}{l}\text { No. of } \\
\text { cases }\end{array}$ & Causal agent/type of event & $\begin{array}{l}\text { No. of } \\
\text { cases }\end{array}$ \\
\hline $\begin{array}{l}\text { Sprains or soft tissue } \\
\text { injuries }\end{array}$ & 280 & $\begin{array}{l}\text { Accidents involving a power } \\
\text { tool or machinery }\end{array}$ & 192 \\
\hline $\begin{array}{l}\text { Haematoma, } \\
\text { contusions or crush } \\
\text { injuries }\end{array}$ & 78 & $\begin{array}{l}\text { Accidents involving a } \\
\text { non-powered tool or item of } \\
\text { equipment }\end{array}$ & 59 \\
\hline $\begin{array}{l}\text { Lacerations or open } \\
\text { wounds }\end{array}$ & 123 & $\begin{array}{l}\text { Accidents involving a motor } \\
\text { vehicle }\end{array}$ & 56 \\
\hline \multirow[t]{2}{*}{ Fractures } & 50 & Chemical or other burns & 154 \\
\hline & & $\begin{array}{l}\text { Chemical poisonings or } \\
\text { inhalation injuries }\end{array}$ & 146 \\
\hline Other (specified) & 50 & Other (specified) & 59 \\
\hline Missing & 805 & Missing & 683 \\
\hline All* & 1386 & All* & 1349 \\
\hline
\end{tabular}

*Totals exceed the number of cases (1348) as several subjects sustained $>1$ injury within the same episode and one had two external causes. 
Table 2 Relationship between consulting with an occupational injury and consulting with a mental health problem

\begin{tabular}{|c|c|c|c|c|c|c|}
\hline Before the index date & Cases N (\%) & Controls N (\%) & $\mathrm{OR}^{*}$ & $95 \% \mathrm{Cl}$ & $p$ Value & $\begin{array}{l}\text { Attributable fraction } \\
\text { in the exposed (\%) }\end{array}$ \\
\hline No mental health consultation & $966(71.7)$ & $5188(78.0)$ & 1 & (reference) & & \\
\hline \multicolumn{7}{|l|}{ Consultation with } \\
\hline Any psychiatric condition & $382(28.3)$ & $1464(22.0)$ & 1.44 & (1.25 to 1.65$)$ & $<0.001$ & 30.5 \\
\hline Psychosis & $132(9.8)$ & $519(7.8)$ & 1.29 & (1.05 to 1.59$)$ & 0.016 & 22.5 \\
\hline Schizophrenia & $3(0.2)$ & $19(0.3)$ & 0.74 & (0.22 to 2.50$)$ & 0.63 & - \\
\hline Neurosis & $298(22.1)$ & $1139(17.1)$ & 1.41 & (1.21 to 1.64$)$ & $<0.001$ & 29.0 \\
\hline Personality problem & $34(2.5)$ & $137(2.1)$ & 1.20 & (0.82 to 1.76$)$ & 0.35 & 16.7 \\
\hline Other mental health condition & $50(3.7)$ & $166(2.5)$ & 1.53 & (1.10 to 2.14 ) & 0.012 & 34.6 \\
\hline
\end{tabular}

subjects), while hypnotics, anxiolytics and antidepressants were commonly prescribed treatments. The median time from first mental health diagnosis to the index date (duration of illness) was 5.3 years, IQR 2.2 to 11.6 years.

Table 2 presents associations of occupational injury with ever having consulted with a mental health problem prior to the index date and with specific categories of psychiatric illness. A statistically significant association was found for mental health problems overall, the odds of injury being raised some $44 \%$ $(p<0.001)$. Statistically significant associations were also found with consultations related specifically to psychosis (OR 1.29, $\mathrm{p}=0.016$ ), neurosis (OR 1.41, $\mathrm{p}<0.001$ ) and certain other mental health conditions (OR 1.53, $\mathrm{p}=0.012$ ). Associations with mental health consultations more than 12 months before the index date were broadly similar (see online supplementary table S1). The overall attributable fraction among exposed persons was $30.5 \%$, and the corresponding population attributable fraction was $8.6 \%$.

Table 3 shows associations between occupational injury consultation and being prescribed psychotropic drugs before the index date. The odds of injury consultation were raised 57\% for patients prescribed any of the drugs in comparison with subjects who had never had such a prescription, and risks were even higher in relation to hypnotics (OR 1.63) and anxiolytics (OR 1.74). All findings were highly significant statistically $(\mathrm{p}<0.001)$. Associations with prescription in the previous 12 months were similar, although analyses were based on smaller numbers (see online supplementary table S2).

For antidepressants it proved possible to distinguish risks by some major subcategories of treatment. A total of 711 subjects had taken a tricyclic antidepressant and 700 subjects a selective serotonin reuptake inhibitor (SSRI) before the index date; however, monamine oxidase inhibitors and 'other' antidepressant drugs were taken too infrequently to warrant further consideration. Risks of injury consultation were significantly elevated, and to a similar extent, for both of the main classes of antidepressant: OR for tricyclic antidepressants, 1.39 (95\% CI 1.14 to 1.69 ), $\mathrm{p}=0.001$; OR for SSRIs, 1.34 (95\% CI 1.09 to 1.65), $\mathrm{p}=0.005$. Attributable fractions in exposed subjects ranged from $27 \%$ (antidepressants) to $42.5 \%$ (anxiolytics). The corresponding population attributable fraction for taking a psychotropic drug ever before the index event was 9.9\%.

As patients with mental health problems are commonly treated with psychotropic drugs, and psychotropic drugs are mostly prescribed for mental illness, the relative contribution of each to risk of injury bears clarification. We therefore compared risks in subjects with a mental health diagnosis but no prior psychotropic drug treatment, and those with a mental health diagnosis who did receive a psychotropic drug, taking as a reference subjects with neither consultation for mental illness nor prescription of psychotropic medication (table 4). (The permutation 'drug treatment without mental health diagnosis' was not considered informative as the 1328 codes used to identify mental health problems will not have perfectly captured every mental health case. For example, 'tiredness', which was not included, would be indeterminate, having physical as well as psychological causes.) Risks were significantly elevated even in subjects who had a mental health consultation but no psychotropic drug prescription prior to the injury consultation (OR 1.41, $\mathrm{p}=0.001)$.

Risks varied little according to the type or external cause of injury (see online supplementary table S3). They were significantly elevated also among severe cases (those involving fracture or amputation or hospital attendance) when assessed separately:

Table 3 Relationship between consulting with an occupational injury and being prescribed a hypnotic, anxiolytic or antidepressant drug

\begin{tabular}{|c|c|c|c|c|c|c|}
\hline Before the index date & $\begin{array}{l}\text { Cases }(n=1348) \\
N(\%)\end{array}$ & $\begin{array}{l}\text { Controls }(n=6652) \\
N(\%)\end{array}$ & $\mathrm{OR}^{*}$ & $95 \% \mathrm{Cl}$ & $\mathrm{p}$ Value & $\begin{array}{l}\text { Attributable fraction } \\
\text { in the exposed (\%) }\end{array}$ \\
\hline Never prescribed any of these drugs & $982(72.8)$ & $5336(80.2)$ & 1 & & & \\
\hline Prescribed one or more of these drugs & $366(27.2)$ & $1316(19.8)$ & 1.57 & (1.36 to 1.81$)$ & $<0.001$ & 36.3 \\
\hline \multicolumn{7}{|l|}{ Prescribed } \\
\hline Antidepressants & $244(18.1)$ & $945(14.2)$ & 1.37 & (1.17 to 1.62$)$ & $<0.001$ & 27.0 \\
\hline Hypnotics & $201(14.9)$ & $659(9.9)$ & 1.63 & (1.37 to 1.94$)$ & $<0.001$ & 38.7 \\
\hline Anxiolytics & $147(10.9)$ & $443(6.7)$ & 1.74 & (1.42 to 2.12 ) & $<0.001$ & 42.5 \\
\hline
\end{tabular}

${ }^{*}$ Adjusted for problem drinking.

Some subjects had more than one treatment. 
Table 4 The overlap between mental health problems and psychotropic prescriptions and their relation to consulting with an occupational injury

\begin{tabular}{|c|c|c|c|c|c|}
\hline Before the index date & Cases $(n=1348) N(\%)$ & Controls $(n=6652) N(\%)$ & OR* & $95 \% \mathrm{Cl}$ & p Value \\
\hline No prescription or MHP & $854(63.4)$ & $4814(72.3)$ & 1 & & \\
\hline MHP but no prescription & $128(9.5)$ & $522(7.8)$ & 1.41 & (1.15 to 1.74$)$ & 0.001 \\
\hline Both MHP and a prescription & $254(18.8)$ & $942(14.2)$ & 1.60 & (1.36 to 1.89$)$ & $<0.0001$ \\
\hline
\end{tabular}

${ }^{*}$ Adjusted for problem drinking.

MHP, mental health problem. 'Prescription'-any of the classes of psychotropic drug listed in table 3.

OR $1.45,95 \%$ CI 1.00 to 2.10 for previous psychiatric consultation and $1.55,95 \%$ CI 1.07 to 2.26 for previous prescription of a psychotropic drug. Risks overall differed only marginally when analyses were carried out separately for men and women (data available upon request).

\section{DISCUSSION}

These data support the conclusion of our previous review, ${ }^{1}$ that mental illnesses and prescribed psychotropic treatments moderately increase the risks of occupational injury. Risks were elevated $44 \%$ overall in relation to mental health problems and $57 \%$ overall in relation to psychotropic drug treatments. There was evidence that the effects of having a mental health condition are not solely a consequence of psychotropic medication. For patients taking common classes of antidepressants, we estimate that risks of injury are raised about $35-40 \%$. The data further indicate that approximately 1 in 10 of all workplace injuries may be attributable to mental health conditions or psychotropic medication, the potentially avoidable fraction being higher (about 30-40\%) among individuals with such health problems or taking such prescribed treatments.

Our study had several strengths and a few limitations. The database allowed us to identify a large sample of occupational injuries across Britain, together with a selection of age-matched, sex-matched and location-matched controls. Almost everyone in Britain registers with a family doctor for services that can be freely accessed at the point of delivery. Thus, general practice patient lists offer a sampling frame that is generally representative of the total population. Moreover, the CPRD database, which has been shown empirically to have a high degree of completeness (>97\%) and validity for many measures, ${ }^{29}{ }^{30}$ is likely to capture a very high proportion of acute injuries presenting to medical services (hospital attendances, which are logged within the database, are also free at the point of care, while accidents are rarely treated privately). Set against this, we could not investigate injuries that were only self-treated or mishaps resulting only in damage to property or near miss events. The complexity of the coding system was such that we may not have discovered every case of occupational injury or mental illness within the sampling frame. However, errors of omission would be unlikely to cause bias since the process of case ascertainment was independent of the exposures of interest.

A more significant limitation of the CPRD is that it does not maintain a reliable record of patients' occupations. Thus, while cases would have been selected from those in work, some controls may have been unemployed; cases may also have been drawn more often from manual occupations than controls. Bias might arise if controls over-represented the prevalence of mental illnesses or treatments for disorders that prevent work, or if these were more common in manual jobs. However, as we have demonstrated elsewhere, ${ }^{31}$ the resultant bias is likely to be small in practice. (This is because the excess prevalence in controls would reflect the weighted average of risks in subgroups, and be diluted, on the one hand, by a low background rate of unemployment and, on the other hand, by the small difference in risk between manual and non-manual occupations. Moreover, potential biases would act in opposite directions.)

The CPRD record tends to lack information on the circumstances of occupational injury and some cases could have been injured through the fault of third parties rather than themselves. Furthermore, some codes were ambiguous as to occupational causation (such that $15 \%$ of cases were possibly, but not probably occupational, as judged independently by two of us (KTP and $\mathrm{ECH}$ ) blinded to exposure status). Such errors would, if anything, bias risk estimates towards the null and cannot explain the elevation in risks that we observed. Risks of workplace injury could also have been reduced by healthy worker selection effects in the study population-for example, subjects with health problems opting for work with less injury potential or being screened out of hazardous work. This well-known effect would not compromise the internal validity of our study (as risks in workplaces would truly be lower), but is a threat to external validity, as simple extrapolation to unselected workforces could lead to an underestimation of risks.

A notable strength of the CPRD is that for each subject we could access a hugely detailed medical record, in which mental health diagnoses and treatments had been contemporaneously logged, independently of the injury consultation, and with full information on dates of events. The relative timing of events was thus established, although, as a further safeguard against the possibility that errors in the coding of dates masked an element of reverse causation, we explored associations with diagnoses made at least 12 months before the injury consultation in a sensitivity analysis: risk estimates were unchanged.

A further sensitivity analysis explored risks by nature and by external cause of injury, and found them to be broadly and generally elevated (see online supplementary table S3). Non-specificity of effect raises a concern that risk estimates may have been inflated by an overall propensity among cases to consult a family doctor (which is a requirement both of case definition and of qualifying exposures), but a similar significant magnitude of effect among severe cases (those seen in hospitals and those with fractures and amputations) tends to argue against important bias arising in this fashion.

The findings from this study are broadly compatible with other published data on mental illness and accident risk. Thus, in our previous review, ${ }^{1} 21$ of 22 risk estimates across 11 studies were elevated, $60 \%$ of them significantly so at the $5 \%$ level, and with a median RR of 1.5 . The four largest studies ( $>1400$ subjects analysed ${ }^{5} 71416$ ), including a large multistage probability sample from the US Health and Retirement Study cohort, ${ }^{16}$ provided risk estimates ranging from 1.07 to 1.47 . However, studies mostly took self-reported low mood on a screening questionnaire as the basis for exposure definition, and only 6 of the 22 effect estimates were based on a physician's diagnosis of mental illness. 
Earlier findings on psychotropic drugs and occupational injury risk have been more mixed. In our review, ${ }^{1} 13$ of 25 risk estimates (from nine studies) were increased, five of them significantly, the median RR being 1.2. However, the spread of risk estimates was wider than for mental illness, and two highquality case-control studies with date of event information (to limit scope for reverse causation) reached different conclusions. Voaklander et $a l^{14}$ reported that prescription of anxiolytics, sedatives or hypnotics in the preceding 30 days was associated with a threefold increase in odds of hospital attendance with work-related injury, whereas Gilmore et $a l^{20}$ in a study of similar design, found much lower RRs (0.8 in men and 1.5 in women). Two other studies favoured a more than doubling of risk from medication, ${ }^{17} 18$ although both had the potential for inflationary bias through reverse causation-in Wadsworth et $a l^{18}$ for example, the taking of sleeping pills related to the 14 days prior to questioning whereas injuries might have occurred up to a year beforehand. Studies mostly evaluated risks from hypnotics, anxiolytics and sedatives (or did not specify the class of agent), there being relatively few investigations of injury risk from antidepressants and antipsychotics, and, in contrast to this report, none that estimated risks by major classes of antidepressant. Hence, our findings, as well as providing estimates of risk based on accurate date of event information, provide a greater depth of information on specific agents.

On balance, we conclude that a range of common mental health illnesses and classes of psychotropic treatment contribute to an important, minority of workplace injury events. Absolute risks do not justify exclusion of individuals from employment, especially as individualised assessment may reveal factors that mitigate the risk of injury or its impact. However, the data suggest a need to exercise caution in the occupational placement of individuals with such problems, especially in relation to work that carries an unusual degree of risk or special responsibility for the safety of others.

Acknowledgements This study was support by a grant from the Institution of Occupational Safety and Health (IOSH) and by programme funding from the Medical Research Council. Access to the CPRD data was granted under an MRC licence. We wish to thank staff members of the MHRA, including Professor Tjeerd Van Staa, for their support and Dr Martin Frisher for supplying us the list of Read codes used to identify cases of mental illness within the CPRD database.

Collaborators Professor Tjeerd Van Staa from the CPRD.

Contributors KTP and DC designed the study and led in analysis. KTP, with ECH and $\mathrm{CHL}$, decided on a plan of coding and executed it. SDA conducted the statistical analyses. KTP gained the permissions for data access and obtained the data All authors contributed to interpretation. KTP wrote the first draft of the manuscript and all authors shared in its revision. KTP acts a guarantor for the work.

Funding Institution of Occupational Safety and Health and the Medical Research Council (Grant ref R/1106/2).

\section{Competing interests None.}

Ethics approval Medicines and Health Products Regulatory Agency.

Provenance and peer review Not commissioned; externally peer reviewed.

\section{REFERENCES}

1 Palmer KT, Harris EC, Coggon D. Chronic health problems and risk of accidental injury in the workplace: a systematic literature review. Occup Environ Med 2008;65:757-64.

2 da Silva MC, Fassa AG, Kriebel D. Minor psychiatric disorders among Brazilian ragpickers: a cross-sectional study. Environ Health 2006;5:17.
3 Edlund MJ, Conrad C, Morris P. Accidents among schizophrenic outpatients. Compr Psychiatry 1989;30:522-6.

4 Frone MR. Predictors of work injuries among employed adolescents. J App/ Psychol 1998;83:565-76.

5 Nakata A, Ikeda T, Takahashi M, et al. Impact of psychosocial job stress on non-fatal occupational injuries in small and medium-sized manufacturing enterprises. Am J Ind Med 2006;49:658-69.

6 Zwerling C, Sprince NL, Wallace RB, et al. Occupational injuries among agricultural workers 51 to 61 years old: a national study. J Agr Saf Health 1995;1:273-81.

7 Zwerling C, Sprince NL, Wallace RB, et al. Risk factors for occupational injuries among older workers: an analysis of the Health and Retirement Study. Am J Public Health 1996:86:1306-9.

8 Ghosh AK, Bhattacherjee A, Chau N. Relationships of working conditions and individual characteristics to occupational injuries: a case-control study in coal miners. J Occup Health 2004;46:470-8.

9 Peele PB, Tollerud DJ. Depression and occupational injury: results of a pilot investigation. J Occup Environ Med 2005;47:424-7.

10 Sprince NL, Park H, Zwerling C, et al. Risk factors for machinery-related injury among lowa farmers: a case-control study nested in the Agricultural Health Study. Int J Occup Environ Health 2002;8:332-8.

11 Sprince NL, Zwerling C, Lynch CF, et al. Risk factors for agricultural injury: a case-control analysis of lowa Farmers in the Agricultural Health Study. J Agric Saf Health 2003:9:5-18.

12 Sprince NL, Park H, Zwerling C, et al. Risk factors for animal-related injury among lowa large-livestock farmers: a case-control study nested in the Agricultural Health Study. J Rural Health 2003;19:165-73.

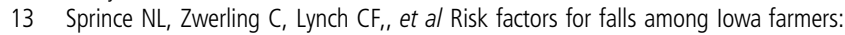
a case-control study nested in the Agricultural Health Study. Am J Ind Med 2003:44:265-72.

14 Voaklander DC, Kelly KD, Rowe BH, et al. Pain, medication, and injury in older farmers. Am J Ind Med 2006;49:374-82.

15 Park H, Sprince NL, Lewis MQ, et al. Risk factors for work-related injury among male farmers in lowa: a prospective cohort study. J Occup Environ Med 2001:43:542-7.

16 Zwerling C, Sprince NL, Davis CS, et al. Occupational injuries among older workers with disabilities: a prospective cohort study of the Health and Retirement Survey, 1992 to 1994. Am J Public Health 1998;88:1691-5.

17 Proctor RC. Prescription medication in the workplace: Occupational absenteeism, accidents, and performance when using non-psychoactive and psychoactive medication. N C Med J 1981;42:545-7.

18 Wadsworth EJ, Moss SC, Simpson SA, et al. Preliminary investigation of the association between psychotropic medication use and accidents, minor injuries and cognitive failures. Hum Psychopharmacol 2003;18:535-40.

19 Chau N, Mur JM, Benamghar L, et al. Relationships between certain individual characteristics and occupational injuries for various jobs in the construction industry: a case-control study. Am J Ind Med 2004;45:84-92.

20 Gilmore TM, Alexander BH, Mueller BA, et al. Occupational injuries and medication use. Am J Ind Med 1996;30:234-9.

21 Moll van Charante AW, Mulder PG. Perceptual acuity and the risk of industrial accidents. Am J Epidemiol 1990;131:652-63.

22 Montastruc JL, Charlet JP. Use of benzodiazepines and industrial injuries. Service Medical Interentreprises de Toulouse, France. Eur J Clin Pharmacol 1992;42:553-4.

23 Pickett W, Chipman ML, Brison RJ, et al. Medications as risk factors for farm injury. Accid Anal Prev 1996:28:453-62.

24 Bhattacherjee A, Chau N, Sierra CO, et al. and Lorhandicap Group. Relationships of job and some individual characteristics to occupational injuries in employed people: a community-based study. J Occup Health 2003;45:382-91.

25 Tiesman HM, Peek-Asa C, Whitten $\mathrm{P}$, et al. Depressive symptoms as a risk factor for unintentional injury: a cohort study in a rural county. Inj Prev 2006;12:172-7.

26 Cherry N, Burstyn I, Beach J. Mental ill-health and second claims for work-related injury. Occup Med 2012;62:462-5.

27 Wally T, Mantgani A. The UK general practice research database. Lancet 1997;350:1097-9.

28 Frisher M, Crome I, Macleod J, et al. Substance misuse and psychiatric illness: prospective observational study using the general practice research database. J Epidemiol Community Health 2005;59:847-50.

29 Jick $H$, Jick SS, Derby LE. Validation of information recorded on general practitioner based computerised data resource in the United Kingdom. BMJ 1991;302:766-8.

30 Hollowell J. General Practice Research Database (GPRD): scope and quality of data. London: Office of Population Censuses and Statistics, 1994.

31 Palmer KT, Kim M, Coggon D. Bypassing the selection rule in choosing controls for a case-control study. Occup Environ Med 2010;67:872-7. 